\title{
The Effect of Inactivation of Aldehyde Dehydrogenase on Pheromone Production by the Gut Bacteria of an Invasive Bark Beetle, Dendroctonus Valens (LeConte)
}

\section{Qingjie Cao}

Hebei Agricultural University

Tuuli-Marjaana Koski

Institute of Zoology Chinese Academy of Sciences

Huiping Li

Hebei Agricultural University

Jianghua Sun ( $\nabla$ sunjh@ioz.ac.cn )

Institute of Zoology Chinese Academy of Sciences https://orcid.org/0000-0002-9465-3672

\section{Research Article}

Keywords: Transcriptome, Gut facultative anaerobes, Verbenone, Mutants

Posted Date: February 10th, 2022

DOI: https://doi.org/10.21203/rs.3.rs-1309915/v1

License: (c) (i) This work is licensed under a Creative Commons Attribution 4.0 International License.

Read Full License 


\section{Abstract}

Semiochemical-based strategies are important for bark beetle management worldwide. One of the most destructive invasive bark beetles, the causal agent of mass pine (Pinus sp.) mortality in China, is the red turpentine beetle (RTB) Dendroctonus valens (LeConte), originating from North America. For this species, verbenone pheromone regulates the beetles' attack density in a dosage dependent manner. In addition, we have previously shown that RTB's gut bacteria is involved in the pheromone production under both anaerobic and micro-oxygen environments. However, although some investigations of anaerobic gut bacteria of bark beetles have been made, functional verification of their role at molecular level is still lacking. To clarify the function of gut bacteria in verbenone production, we investigated the activity of key genes of the primary gut bacteria involved in verbenone production in $D$. valens under anaerobic environment. These key genes (aldehyde dehydrogenase) identified by transcriptome analysis were then knocked out by homologous recombination to obtain mutant bacteria strains. Our results show that these mutants had significantly decreased ability to convert the monoterpene precursor to verbenone compared to the wild type bacteria. Our findings provide further evidence of the mechanism of pheromone production of $D$. valens and a new perspective for functional studies of gut bacteria in general.

\section{Introduction}

Insect gut microbiome performs myriad ecological functions (Dillon and Dillon 2004; Engel and Moran 2013) such as absorption and utilization of nutrients (Kaufman and Klug 1991; Breznak 2002), improving resistance against invasion of pathogens and natural enemies (Shao et al. 2017; Koch and SchmidHempel 2011), boosting host immune response (Mikonranta et al. 2014), degrading harmful xenobiotics (Tago et al. 2015; Mason et al. 2016) and mediating plant-insect interactions by detoxificaticating host defense chemicals (Mason et al. 2014; Wang et al.2020). Microbiota is also involveld in other key functions in insects' life, such as pheromone production. For example, gut microbiota is largely responsible for the production of aggregation pheromones of locusts, sex pheromones of cockroaches (Dillon et al. 2002), and influence the mating preference of Drosophilla meladella (Sharon et al. 2010).

Bark beetles are economically important insect pests of conifer and broadleaf trees, and pheromonebased mass trapping and push-pull techniques are essential for their successful management (Wermelinger 2004; Witzgall et al. 2010). A large proportion of bark beelte pheromones are composed of monoterpenoid oxides (Wood 1982; Blomquist et al. 2010). For example, a-pinene is not only an important host defensive monoterpene, but also a precursor for the bark beetle pheromone verbenone (Blomquist et al. 2010; Gitau et al. 2013). Many micro-organisms have been implicated to be involved in the bioconversion of precursors to terpenes and in the synthesis of terpenoid pheromones. In Ips paraconfusus, for instance, gut bacteria oxidize a-pinene to pheromone verbenol (Brand et al. 1975). Pheromone synthesis by microorganisms is conducted by degrading plant compounds, and some investigation of the mechanisms behind this process have also been made. For example, Merlin et al. (2005) suggested that aldehyde oxidase could degrade aldehyde odorant compounds, such as pheromones or plants volatiles. Comparison of in vivo and in vitro physiological data from Drosophila 
melanogaster adults confirmed that aldehyde dehydrogenase (ALDH) was responsible for the detoxification effect of acetaldehyde in vivo (Leal and Barbancho 1992).

Red turpentine beetle Dendroctonus valens LeConte (Coleoptera: Scolytidae), was introduced to China from North America in the 1980s. Despite D.valens is an innocuous secondary pest in its native range, has become a primary tree-killer of Chinese red pine Pinus tabulaeformis (Carr) in the new invasive range, causing substantial economic losses and recieving its status as China's most destructive forest pest. Semiochemical-based management strategies, including pheromone traps, has been successfully implemented in D. valens' control (Sun et al. 2013; Liu et al. 2019 ). Several bioactive volatiles, such as cis-verbenol, trans-verbenol, myrtenol, myrtenal, and verbenone have been idenitified from the gut of this beetle (Zhang et al. 2006; Sun et al. 2013). Verbenone, in general, is an aggregation pheromone of $D$. valens but also acts as an anti-aggregation pheromone in high concentrations (Zhang et al. 2006). The concentration of verbenone in $D$. valens mainly depends on the conversion rate of cis-verbenol and transverbenol to verbenone (Xu et al. 2015).

Previous studies investigating pheromone conversion of D.valens have shown that oxygen concentration inside the gut affecst the rate of pheromone synthesis (Cao et al. 2018). However, Cao et al. (2018) showed that nine out of ten species of gut facultative anaerobic bacteria were able to convert cisverbenol into verbeone under both anaerobic and micro-oxygen environments, facultative anaerobic gut bacteria Enterobacter xiangfangensis having the strongest ability to synthesize this pheromone.

Althought pheromones of $D$. valens have been extensively studied, molecular level confirmation of the function of its gut bacteria in pheromone production is still lacking. To address this knowledge gap, we identified the key bacterial genes involved in $D$. valens' verbenone production under anaerobic conditions. More specificially, we analyzed the ability of the most effective facultative anaerobic gut bacteria $E$. xiangfangensis of $D$. valens to covert cis-verbenol to verbenone. We then identified the key genes responsible for this task via transcriptome analysis, knocked them out by homologous recombination to obtain mutant strains and determined the ability of these mutants to convert the monoterpene precursor into the pheromone product. Our findings will shed light on the molecular basis how gut bacteria participate in the synthesis of pheromones, and provide a new scientific basis for the functional study of gut bacteria and the mechanism of pheromone synthesis of $D$. valens.

\section{Materials And Methods}

\section{Bacterial strains, plasmids, and growth conditions}

Strains used in this study are listed in Table 1. E. xiangfangensis were cultured in Luria-bertani medium (LB medium, per liter, $10 \mathrm{~g}$ of trypton, $5 \mathrm{~g}$ of yeast extract) at $30^{\circ} \mathrm{C}$. E. coli strains were cultured in LB medium at $37^{\circ} \mathrm{C}$. 
Bacterial strains and plasmids used in this work

\begin{tabular}{|c|c|c|}
\hline Strain plasmid & Genotype, properties & Source or reference \\
\hline Strain & Wild type & (Cao et al., 2018) \\
\hline \multicolumn{3}{|c|}{ E.Xiangfangensis } \\
\hline \multicolumn{3}{|l|}{ E.coli } \\
\hline S17-1 ( $\lambda$ pir) & $\begin{array}{l}\text { TpR SmR recA, thi-1, pro, hsdR- } \\
\text { M+RP4:2-Tc:Mu:Km Tn7 } \lambda \text { pir }\end{array}$ & $\begin{array}{l}\text { School of Pharmaceutical Science and } \\
\text { Technology Tianjin University }\end{array}$ \\
\hline \multicolumn{3}{|l|}{ Plasmid } \\
\hline pUC19 & $A m p^{R}$ & $\begin{array}{l}\text { School of Pharmaceutical Science and } \\
\text { Technology Tianjin University }\end{array}$ \\
\hline \multirow[t]{2}{*}{ pRE112 } & & $\begin{array}{l}\text { School of Pharmaceutical Science and } \\
\text { Technology Tianjin University }\end{array}$ \\
\hline & $\mathrm{Cm}^{\mathrm{R}}$, SacB,oriT,oriV & \\
\hline
\end{tabular}

\section{RNA-Seq library construction and sequencing}

We selected the E. xiangfangensis strain as the key strain. After the activation, E. xiangfangensis were cultured in $5 \mathrm{~mL} \mathrm{LB}$ medium at $30^{\circ} \mathrm{C}, 180 \mathrm{rpm}$ for 24 hours until the light absorption value reached 0.5 at the wavelength of $600 \mathrm{~nm}$. Then, $40 \mathrm{ng} / \mathrm{L}$ cis-verbenol was added to the final concentration as the treatment group, and DMSO was added to control.

The bacteria were cultured at $30^{\circ} \mathrm{C}, 180 \mathrm{rpm}$ for another 16 hours and then were collected in a $1.5 \mathrm{~mL}$ tube by centrifugation at $12000 \mathrm{rpm}$ for $3 \mathrm{~min}$. Three replicates were conducted for each group. RNA extraction was performed using the RNeasy Mini Kit (QIAGEN, USA). RNA-Seq library construction and sequencing was completed by Beijing Novo Zhiyuan Sci-Tech Company Limited.

\section{Transcriptome data analysis and synthetic pheromone related gene identification}

Reads were mapped to the reference genome. The reference genome was completed by Beijing Novo Zhiyuan Sci-Tech Company Limited. Building of the reference genome index and alignment of clean reads to the reference genome were done using Bowtie2-2.2.3.

Because the pheromones of $D$. valens are synthesized by the oxidation process (Brand et al. 1975; Blomquist et al. 2010), the genes that belonged to oxidation-related gene families were selected for further analysis. Finally, pheromone-related genes were identified according to results from gene annotation. Based on these results, we chose ALDH as a target gene (see Results) for generating mutant strains without a functioning copy of this candidate gene potentially responsible for pheromone conversion. 


\section{Construction of the gene-deficient mutants}

ALDH gene-deficient mutant strains of E. xiangfangensis were constructed using the homologous, double-cross-over method with the suicide vector pRE112 as previously described (Edwards et al. 1998; Yu et al. 2010; Deng et al. 2018).

Briefly, the upstream and downstream genomic sequences of the ALDH coding sequence were separately amplified using primers listed in Table 2. After ligating using restriction enzyme and digesting pRE112 using ClonExpress II One Step Cloning Kit (Vazyme, China) (Liu et al. 2020), the recombinant plasmid was transferred to the E.coliS17-1 ( $\lambda$ pir) component cells. The positive clones were confirmed by PCR using primers in Table 2 and sequenced.

Table 2

Primers used in this work

\begin{tabular}{|ll|}
\hline Primer name & Primer sequence \\
\hline Ex-ALDH1-up-F & CGACGGCCAGTGCCAAGCTTCGGTCATACCGAGCATCT \\
\hline Ex-ALDH1-up-R & CGGCAAGAAAGAGGTGCGTTCTTCTCTCCAGATGTTTCGT \\
\hline Ex-ALDH1-down-F & ACGAAACATCTGGAGAGAAGAACGCACCTCTTTCTTGCCG \\
\hline Ex-ALDH1-down-R & ATGACCATGATTACGAATTCAGTAGTTACCGTCGCCCA \\
\hline Ex-ALDH1-T1 & GATCAGCGTCTTGCGGTA \\
\hline Ex-ALDH1-T2 & TTCCCATCGCAGACCTCA \\
\hline Ex-ALDH1-T3 & TTCTGCTCGAGATCCACCA \\
\hline
\end{tabular}

The positive E.coli S17-1 ( $\lambda$ pir) colony was cultured in $5 \mathrm{~mL} \mathrm{LB}$ medium at $37{ }^{\circ} \mathrm{C}, 180 \mathrm{rpm}$ for 16 hours, meanwhile the wild type $E$. xiangfangensis were cultured in $5 \mathrm{~mL} \mathrm{LB}$ medium at $30^{\circ} \mathrm{C}, 180 \mathrm{rpm}$. Then, we mixed $1 \mathrm{~mL}$ of each of the above two strains with $3 \mathrm{~mL}$ LB medium and cultured at $30^{\circ} \mathrm{C}, 180 \mathrm{rpm}$ for 24 hours, after which the bacteria were collected and spread in the LB plate $(50 \mathrm{mg} / \mathrm{L}$ chloramphenicol, $50 \mathrm{mg} / \mathrm{L}$ Ampicillin). After culturing overnight, the putative single-cross-mutant clones were confirmed by PCR, and cultured in LB medium for second-round homologous cross-over. The ALDH mutants were obtained by spreading the media in the LB agar plate containing $10 \%$ sucrose and confirmed by PCR with two pairs of primers.

\section{Conversion experiments}

Wild type E. xiangfangensis and its ALDH gene-deficient mutants were cultured in LB medium and incubated for $24 \mathrm{~h}$. A dilution of 1:100 of each isolate was made when cultures were adjusted to an optical density $\left(\mathrm{OD}_{600}\right) \cdot 0.5$. concentration $(40 \mathrm{ng} / \mu \mathrm{l}$ and $200 \mathrm{ng} / \mu \mathrm{l})$ of cis-verbenol was then added into 4 $\mathrm{ml}$ bacterial suspensions and shaken for a further $36 \mathrm{~h}$. Both the wild (control) and mutant $E$. 
xiangfangensis bacteria suspensions contained an equivalent amount of cis-verbenol. All solutions were extracted with hexane and then stored for later chemical analysis to determine verbenone concentration. The conversion experiments followed previously described methods (Cao et al. 2018), with slight modification of incubation and shaking times.

\section{Statistical analysis}

R software (version 3.0.3) was used to for pearson's correlation analysis, and significant correlations were declared at $r>0.8$ or $<-0.8$. Conversion experiment results were analyzed using Dunnett's $T^{3}$ test, and significances were determined at $P<0.05$.

\section{Results}

\section{Transcriptome data analysis}

Statistics of sequencing data of E. xiangfangensis shown in Table 3. These sequence data have been submitted to the GenBank databases under accession number PRJNA798447. The genome of the $E$. xiangfangensis was used as a reference genome (reference genome completed by Beijing Novo Zhiyuan Sci-Tech Company Limited) shown in Table 4.

Table 3

Statistics of sequencing data of Enterobacter xiangfangensis

\begin{tabular}{|llllllll|}
\hline $\begin{array}{l}\text { Sample } \\
\text { name }\end{array}$ & $\begin{array}{l}\text { Raw } \\
\text { reads }\end{array}$ & $\begin{array}{l}\text { Clean } \\
\text { reads }\end{array}$ & $\begin{array}{l}\text { clean } \\
\text { bases }\end{array}$ & $\begin{array}{l}\text { Error } \\
\text { rate }\end{array}$ & Q20 & Q30 & $\begin{array}{l}\text { GC } \\
\text { content }\end{array}$ \\
\hline ExCK1 & 8847502 & 8756726 & $1.32 G$ & 0.02 & 98.55 & 95.27 & 54.5 \\
\hline ExCK2 & 7906310 & 7843966 & $1.18 G$ & 0.02 & 98.58 & 95.32 & 54.17 \\
\hline ExCK3 & 7901156 & 7803404 & $1.18 G$ & 0.02 & 98.65 & 95.56 & 54.68 \\
\hline ExV1 & 7755232 & 7685084 & $1.16 \mathrm{G}$ & 0.02 & 98.75 & 95.71 & 53.86 \\
\hline ExV2 & 7709364 & 7629624 & $1.15 G$ & 0.02 & 98.64 & 95.55 & 54.61 \\
\hline ExV3 & 7635610 & 7575258 & $1.14 G$ & 0.02 & 98.63 & 95.43 & 54.23 \\
\hline ExCK= The control group (DMSO was added); ExV= The treatment group (cis-verbenol was added) \\
\hline
\end{tabular}


Table 4

Transcriptome sequencing and comparison with reference genomes

\begin{tabular}{|lllllll|}
\hline $\begin{array}{l}\text { Sample } \\
\text { name }\end{array}$ & ExCK1 & ExCK2 & ExCK3 & ExV1 & ExV2 & ExV3 \\
\hline Total reads & 8756726 & 7843966 & 7803404 & 7685084 & 7629624 & 7575258 \\
$\begin{array}{l}\text { Total } \\
\text { mapped }\end{array}$ & 8735517 & 7827046 & 7784461 & 7670468 & 7611704 & 7559157 \\
& $(99.76 \%)$ & $(99.78 \%)$ & $(99.76 \%)$ & $(99.81 \%)$ & $(99.77 \%)$ & $(99.79 \%)$ \\
\hline $\begin{array}{l}\text { Multiple } \\
\text { mapped }\end{array}$ & 53548 & 42025 & 48758 & 37661 & 44344 & 39930 \\
Uniquely & $(0.61 \%)$ & $(0.54 \%)$ & $(0.62 \%)$ & $(0.49 \%)$ & $(0.58 \%)$ & $(0.53 \%)$ \\
mapped & 8681969 & 7785021 & 7735703 & 7632807 & 7567360 & 7519227 \\
& $(99.15 \%)$ & $(99.25 \%)$ & $(99.13 \%)$ & $(99.32 \%)$ & $(99.18 \%)$ & $(99.26 \%)$ \\
\hline \multicolumn{7}{l}{ ExCK= The control group (DMSO was added);ExV= The treatment group (cis-verbenol was added) } \\
\hline
\end{tabular}

Overall distribution of expressed genes showed that 262 genes were differentially expressed in the control group (DMSO was added) compared to treatment (cis-verbenol was added), whereby 199 DEGs were upregulated and 63 DEGs were downregulated (Fig.1). The expression of control and treatment also displayed a clear separation based on PCA analysis, and the samples in the group were clustered together (Fig.2). These results show that $D$. valens gut strains have a complex oxidative defense mechanism against monoterpenes.

\section{Pheromone related gene identification}

Gene expression patterns and phylogenetic analysis from transcriptomic data of gut bacteria revealed that aldehyde dehydrogenase (ALDH, Gene ID: GM002204) genes were predominantly expressed in oxidoreductase activity (Fig. 3), and clustered with genes involved in pheromone synthesis and detoxification in other species. Furthermore, the transcription abundance of ALDH and aldehyde-alcohol dehydrogenase $(A D H)$ was significantly upregulated when verbenol was added, and the expression level of ALDH was significantly higher than that of ADH. We therefore considered ALDH as the main candidate gene for $D$. valens pheromone synthesis.

\section{ALDH knock-out}

Following these results from candidate gene identification, we subsequently generated ALDH mutants of E. xiangfangensis by homologous recombination (Edwards et al. 1998; Yu et al. 2010; Deng et al. 2018). ALDH mutant $E$. xiangfangensis showed a shorter PCR product than wild type when using primer T1/T2 or T1/T3 (Fig. 4).

\section{Conversion experiments}


Comparison of cis-verbenol conversion results between the mutant and the wild-type strains of $E$. xiangfangensis at $40 \mathrm{ng} / \mu \mathrm{l}$ and $200 \mathrm{ng} / \mu \mathrm{l}$ concentrations showed that the wild-type strains (control group) had the ability to convert cis-verbenol, whereas this ability was significantly decreased in the ALDH-deficient mutant strain (Fig. 5).

\section{Discussion}

In our previous work, our group has demonstrated that the gut bacteria of $D$. valens have the ability to convert monoterpenes to pheromone products. For example, under aerobic environment, intestinal bacteria isolated from D.valens converted cis-verbenol to verbenone (Xu et al. 2015), and nine out of ten intestinal facultative anaerobic bacteria were able perform this function under different oxygen environments, but the conversion rate increased with increasing oxygen concentration (Cao et al. 2018). In order to investigate the mechanisms of phernomone conversion ability at molecular level, we selected a bacterial strain with the strongest conversion ability ( $E$. xiangfangensis, a facultative anarobe) to analyze its transcriptome with or without cis-verbenol, screened the target genes responsible for the pheromone conversion and investigated the converision ability of the bacteria in the absence of function of these genes.

To our knowledge, our current study is the first one to provide molecular evidence to verify the function of intestinal bacterial in the conversion of monoterpenes to pheromone products under anaerobic conditions. When identifying candidate genes responsible for cis-verbenol conversion, our transcriptome analysis showed that the highest expression level was detected in ALDH gene, which is a functional gene commonly found in intestinal bacteria of $D$. valens as well as other insects (Maeno et al. 2016; Martino et al. 2017). This gene is verified to be involved in detoxification of plant secondary chemicals, and can therefore help the insect to adapt to the chemical defense substances released by the host tree (Zhang et al. 2020). Following a knock-down of the target gene using homologous recombination strains, we observed a strong reduction in pheromone synthesis ability, strongly suggesting the primary role ALDH in pheromone synthesis of E. xiangfangensis. Several pine monoterpenes, such as a-Pinene and cisverbenol are toxic to $D$. valens, but are rendered to non-toxic when converted into aggregation pheromone verbenone by its intestinal bacteria (Xu et al. 2015). Therefore, conversion of plant monoterpernes to pheromones is likely a dual process resulting in both detoxification and pheromone synthesis. ALDH is a key gene in the metabolic pathway (involved also in Limonene degradation) of monoterpene a-Pinene through redox reaction. Since there are no relevant metabolic pathway for the conversion of cis-verbenol to verbenone in $D$. valens's own metabolic machinery, our results indicate that ALDH may be the key gene of intestinal facultative anaerobic bacteria of $D$. valens. involved in the pheromone transformation and potentially detoxification.

This result is in contrast with other studies where gut bacteria does not enhance insect's pheromone synthesis (Hunt et al. 1989; Bell et al. 2003). These inconsistencies might result from different experimental settings, such as use of diverse bacterial communities and nutritional media, which in turn influence both microbial communities and host physiology. Another potential reason for differences 
among current and previous studies investigating pheromone converision of insects is that the cultivation and validation of intestinal facultative anaerobes in this study was carried out in an anaerobic environment, whereas some earlier studies have used atmospheric oxygen concentration (Keeling et al. 2016; Nadeau et al. 2017). Therefore, our simulated intestinal microenvironment may be more accurately reflect the oxygen conditions in insect integtines.

Previous studies on the function of intestinal bacteria mainly focused on their ecological roles (Cao et al. 2018), whereas our current study provides a new methodology for molecular verification of the functions of insects' intestinal microbes. Future work should consider external factors that influence intestinal facultative anaerobic bacteria, such as insect gut hydrogen ion concentration $(\mathrm{pH})$. To better understand the complex symbiotic relationships among bark beetles and their micro-organisms, future studies should also address the functions of these bacteria to $D$. valens development, detoxification, and chemical communication.

\section{Declarations}

\section{Acknowledgements}

This work was supported by the National Natural Science Foundation of China (32088102 and 32061123002), Natinal Key Reserach and Development Program of China (2021YFC2600100) and the Program of the Natural Science Foundation of Hebei Province of China (C2019204244).

\section{Author Contributions}

Sun conceived and designed research; Cao conducted experiments; Cao and Li analyzed data; Cao and Koski wrote this manuscript. All authors read, corrected and approved the manuscript.

\section{Conflict of interest}

The authors declare no conflict of interest.

\section{References}

1. Bell SG, Chen X, Sowden $₫ J$, Xu F, Williams JN, Wong LL (2003) Molecular recognition in (+) - alphapinene oxidation by cytochrome P450cam. J Am Chem Soc 125: 705-714

2. Brand JM, Bracke JM, Markovetz AJ, Wood DL. Browne LE (1975) Production of verbenol pheromone by a bacterium isolated from bark beetles. Nature 254: 136-137

3. Blomquist GJ, Figueroa-Teran R, Aw M et al (2010) Pheromone production in bark beetles. Insect Biochem Mol Biol 40: 699-712

4. Breznak JA (2002) Phylogenetic diversity and physiology of termite gut spirochetes. Integ Comp Biol 42: $313-318$ 
5. Cao Q, Wickham J, Chen L, Ahmad F, Lu M, Sun J (2018) Effect of oxygen on verbenone conversion from cis-verbenol by gut facultative anaerobes of Dendroctonus valens. Front Microbiol 9: 1-10

6. Chernysh S, Kim S, Bekker G et al (2002) Antiviral and antitumor peptides from insects. Proc Nati Acad Sci USA 99: 12628-12632

7. Deng CY, Zhang H, Wu Y et al (2018) Proteolysis of histidine kinase VgrS inhibits its autophosphorylation and promotes osmostress resistance in Xanthomonas campestris. Nat Commun 9: 4791

8. Dillon RJ, Vennard CT, Charnley AK (2002) A note: gut bacteria produce components of a locust cohesion pheromone. J Appl Microbiol 92: 759-763

9. Dillon RJ, Dillon VM (2004) The gut bacteria of insects: nonpathogenic interactions. Annu Rev Entomol 49: 71-92

10. Edwards RA, Keller LH, Schifferli DM (1998) Improved allelic exchange vectors and their use to analyze 987P fimbria gene expression. Gene 207: 149-157

11. Engel P, Moran NA (2013) The gut microbiota of insects-diversity in structure and function. FEMS Microbiol Rev 37: 699-735

12. Hunt DWA, Borden JH, Lindgren BS, Gries G (1989) The role of autoxidation of a-pinene in the production of pheromones of Dendroctonus ponderosae (Coleoptera:Scolytidae). Can J Forest Res 19: $1275-1282$

13. Kaufman MG, Klug MJ (1991) The contribution of hindgut bacteria to dietary carbohydrate utilization by crickets (Orthoptera:Gryllidae). Comp Biochem Physiol 98: 117-123

14. Keeling Cl, Li M, Sandhu HK, Henderson H,Yuen MMS, Bohlmann J (2016) Quantitative metabolome, proteome and transcriptome analysis of midgut and fat body tissues in the mountain pine beetle, Dendroctonus ponderosae Hopkins, and insights into pheromone biosynthesis. Insect Biochem Mol Biol 70: 170-183

15. Koch H, Schmid-Hempel P (2011) Socially transmitted gut microbiota protect bumble bees against an intestinal parasite. Proc Natl Acad Sci USA 108: 19288-19292

16. Leal J, Barbancho M (1992) Acetaldehyde detoxification mechanisms in Drosophila melanogaster adults involving aldehyde dehydrogenase (ALDH) and alcohol dehydrogenase (ADH) enzymes. Insect Biochem Molec Biol Vol 22: 885-892

17. Liu Z, Mi G, Raffa K, Sun J (2019) Physical contact, volatiles, and acoustic signals contribute to monogamy in an invasive aggregating bark beetle. Insect Sci 1-13

18. Liu F, Wickham J, Cao Q, Lu M, Sun J (2020) An invasive beetle-fungus complex is maintained by fungal nutritional-compensation mediated by bacterial volatiles. ISME J 14: 2829-2842

19. Maenoa S, Tanizawa Y, Kanesaki Y et al (2016) Genomic characterization of a fructophilic bee symbiont Lactobacillus kunkeei reveals its niche-specific adaptation. Syst Appl Microbiol 39: 516526 
20. Martino ME, Ma D, Leulier F (2017) Microbial influence on Drosophila biology. Curr Opin Microbiol 38 : $165-170$

21. Mason CJ, Couture JJ, Raffa KF (2014) Plant-associated bacteria degrade defense chemicals and reduce their adverse effects on an insect defoliator. Oecologia 175: 901-910

22. Mason CJ, Lowe-Power TM, Rubert-Nason KF, Lindroth RL, Raffa KF (2016) Interactions between bacteria and aspen defense chemicals at the phyllosphere-herbivore interface. J Chem Ecol 42: 193201

23. Merlin C, Francois M, Bozzolan F, Pelletier J, Jacquin-Joly E, Maıbeche-Coisne M (2005) A new aldehyde oxidase selectively expressed in chemosensory organs of insects. Biochem Bioph Res Co 332: 4-10

24. Mikonranta L, Mappes J, Kaukoniitty M, Freitak D (2014) Insect immunity: oral exposure to a bacterial pathogen elicits free radical response and protects from a recurring infection. Front Zool 11: 23

25. Nadeau JA, Petereit J, Tillett RL et al (2017) Comparative transcriptomics of mountain pine beetle pheromone biosynthetic tissues and functional analysis of CYP6DE3. BMC Genomics 18: 311-326

26. Qiu J (2013) China battles army of invaders. Nature 503: 450-451

27. Shao Y, Chen B, Sun C, Ishida K, Hertweck C, Boland W (2017) Symbiont-derived antimicrobials contribute to the control of the lepidopteran gut microbiota. Cell Chem Biol 24: 66-75

28. Sharon G, Segal D, Ringo JM, Hefetz A, Zilber-Rosenberg I, Rosenberg E (2010) Commensal bacteria play a role in mating preference of Drosophila melanogaster. Proc Natl Acad Sci USA 107: 2005120056

29. Sun J, Lu M, Gillette NE, Wingfield MJ (2013) Red turpentine beetle: innocuous native becomes invasive tree killer in China. Annu Rev Entomol 58: 293-311

30. Tago K, Kikuchi Y, Nakaoka S, Katsuyama C, Hayatsu M (2015) Insecticide applications to soil contribute to the development of Burkholderia mediating insecticide resistance in stinkbugs. Mol Ecol 24: 3766-3778

31. Tillman JA, Seybold SJ, Jurenka RA, Blomquist GJ (1999) Insect pheromones-an overview of biosynthesis and endocrine regulation. Insect Biochem Molec 29: 481-514

32. Wang J,Gao Z,Yang M et al (2020) Geographically isolated Colorado potato beetle mediating distinct defense responses in potato is associated with the alteration of gut microbiota. J Pest Sci 93:379390

33. Wermelinger B (2004) Ecology and management of the spruce bark beetle Ips typographus-a review of recent research. For Ecol Manage 202: 67-82

34. Wood DL (1982) The role of pheromones, kairomones, and allomones in the host selection and colonization behavior of bark beetles. Annu Rev Entomo 27: 411-446

35. Witzgall P, Kirsch P, Cork A (2010) Sex pheromones and their impact on pest management. J Chem Ecol 36: 80-100 
36. Xu L, Lou QL, Cheng C, Lu ML, Sun J (2015) Gut-associated bacteria of Dendroctonus valens and their involvement in verbenone production. Microb Ecol 70: 1012-1023

37. Yu C, Cheng Xi, Zhao Z, Zhang C, Li Y, Wu T (2010) Construction and Characterization of a Salmonella Choleraesuis C78-1 $\Delta$ crp Deletion Mutan. Acta Veterinaria et Zootechnica Sinica 41: 587593

38. Zhang L, Sun J, Clarke SR (2006) Effects of verbenone dose and enantiomer on the interruption of response of the Red Turpentine Beetle, Dendroctonus valens LeConte (Coleoptera: Scolytidae), to its kariomones. Environ Entomol 35: 655-660

39. Zhang W, Yu HY, Lv YX et al (2020) Gene family expansion of pinewood nematode to detoxify its host defence chemicals. Mol Ecol 29: 940-955

\section{Figures}




\section{ExVvsExCK}

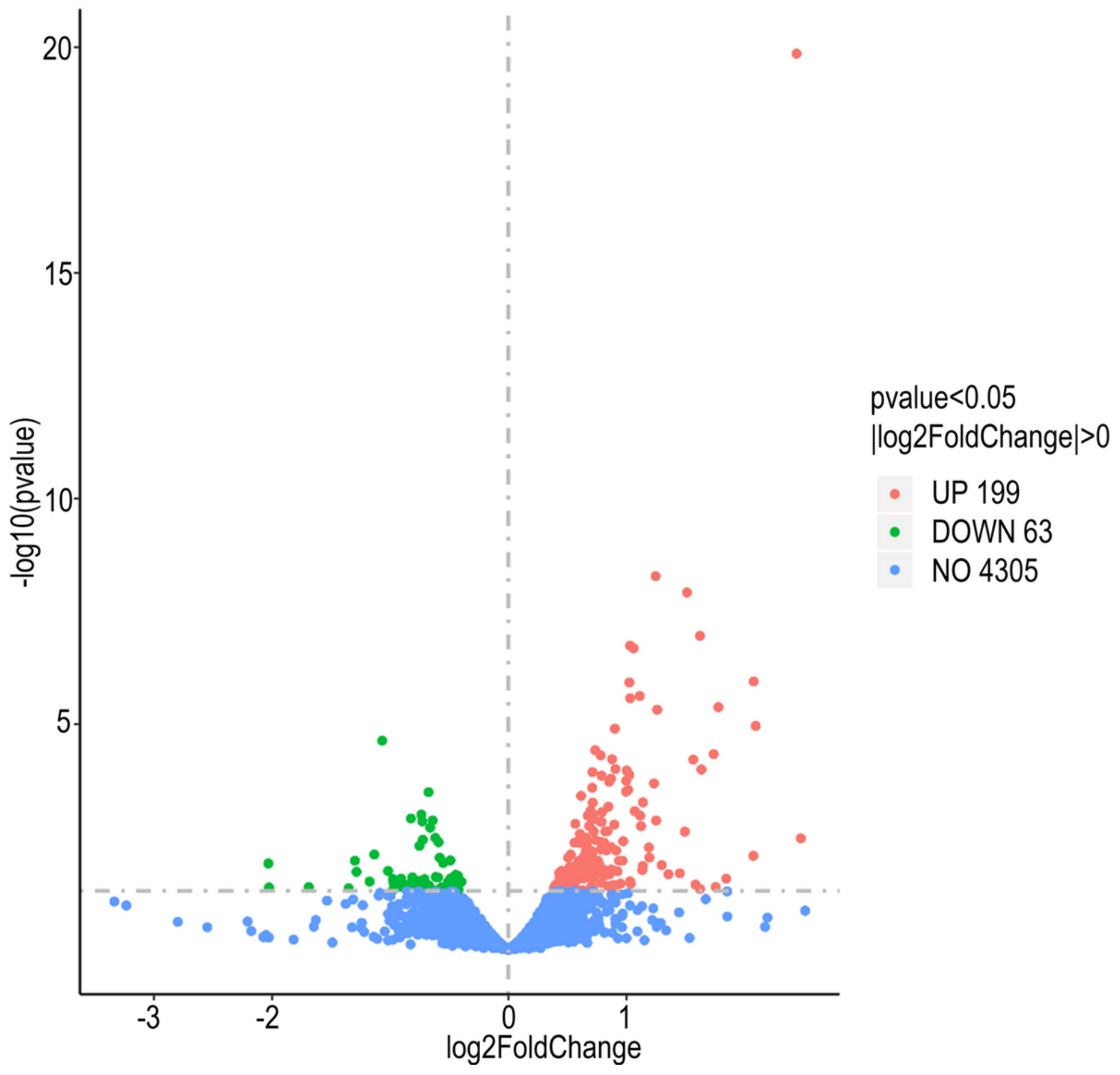

Figure 1

Overall distribution of differently expressed genes of Enterobacter xiangfangensis, the primary bacteria invoveld in verbanone conversion of $D$. valens in the presense and absence of the pheromone precursor cis-verbenol. Significantly differentially expressed genes marked with red (elevated) and green (degreased) dots. Non-significant differences are indicated by blue dots. ExCK vs ExV= The difference genes of control group (DMSO was added) and treatment group (cis-verbenol was added) were compared. 


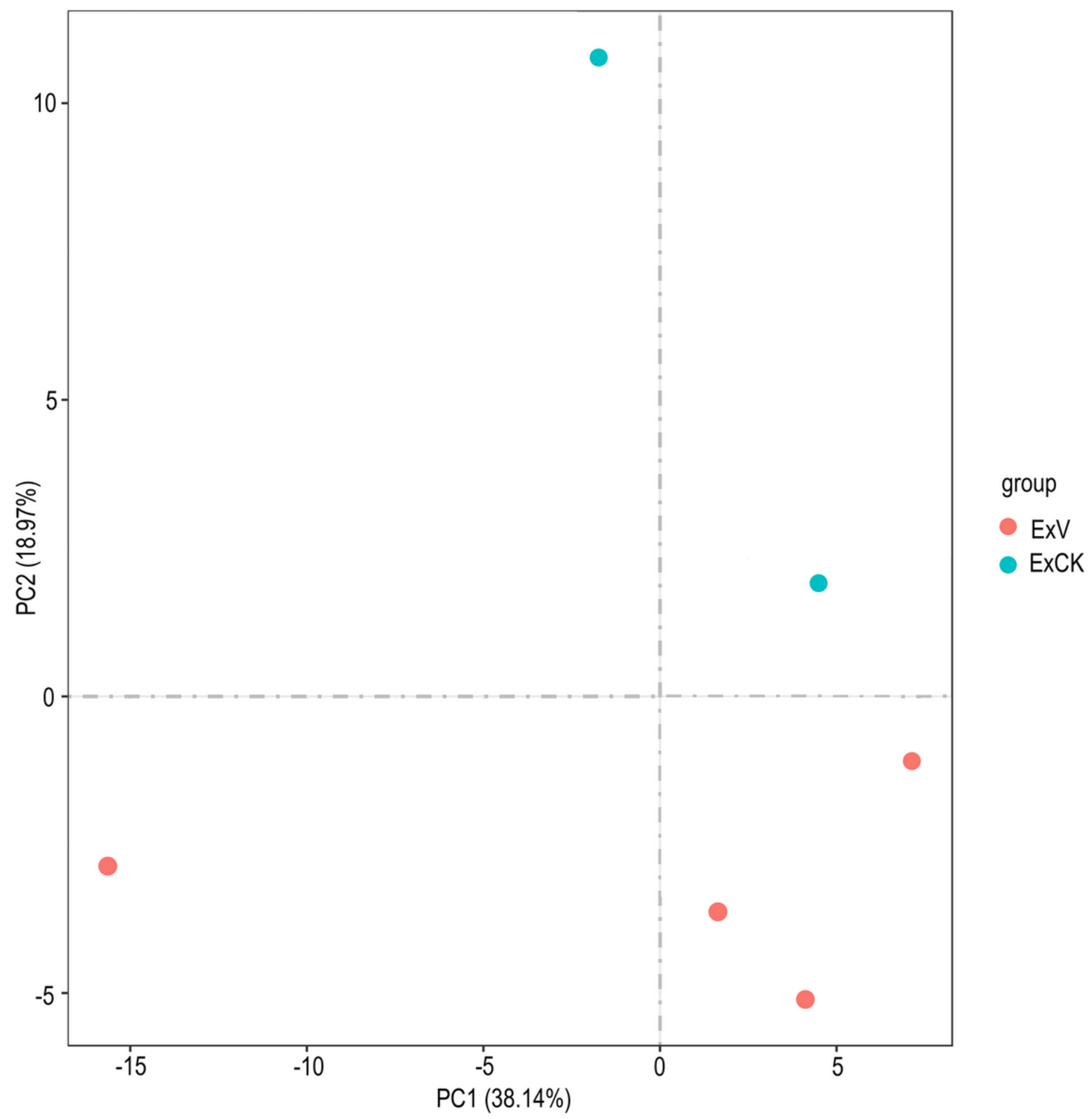

Figure 2

PCA plot of expressed genes of Enterobacter xiangfangensis, the primary bacteria invoveld in verbanone conversion of $D$. valens, in the presense and absence of the pheromone precursor cis-verbenol. PCA adopts the calculation method of linear algebra. ExCK= The control group (DMSO was added) $\triangle \mathrm{ExV}=\mathrm{The}$ treatment group (cis-verbenol was added). 


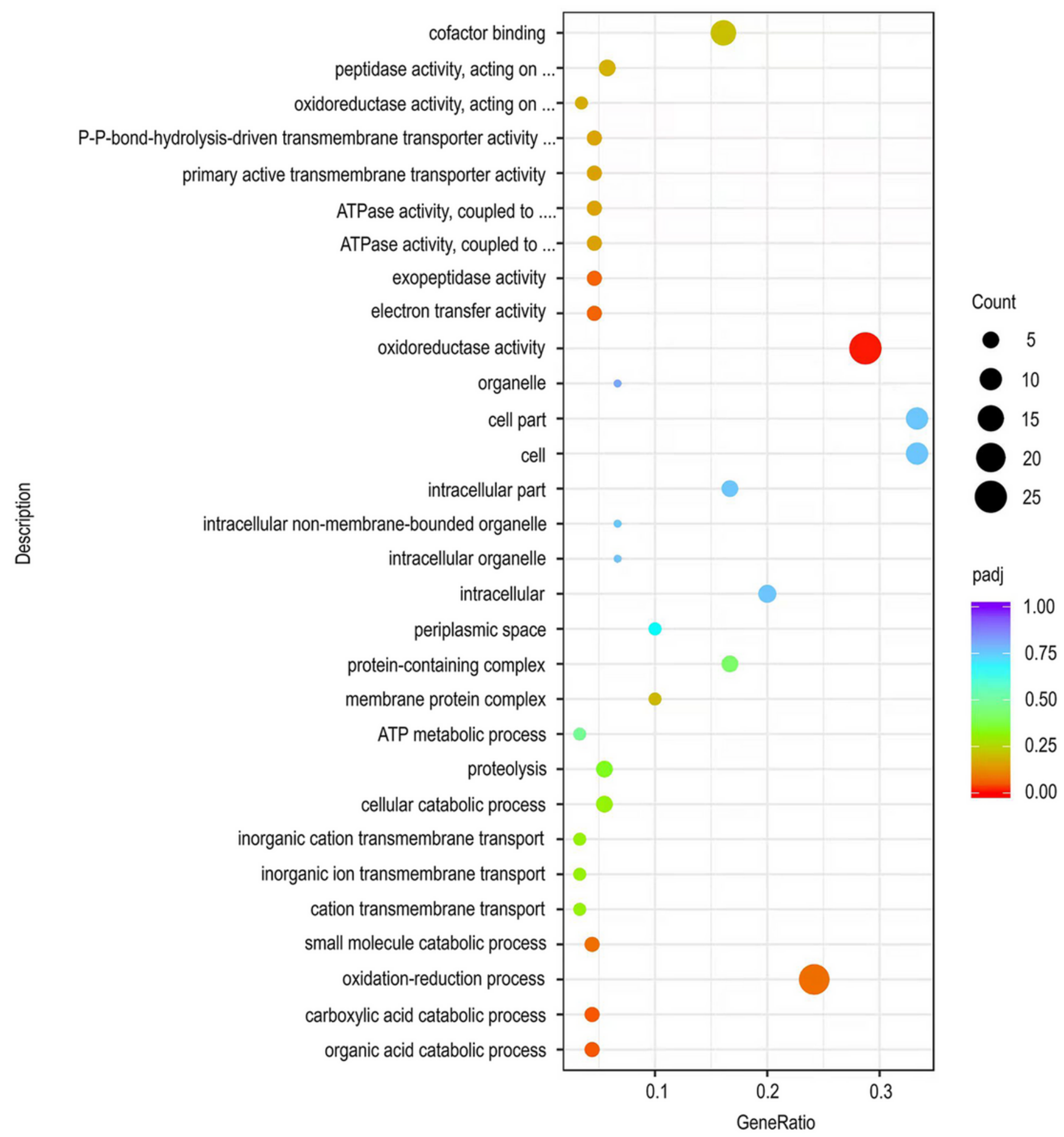

\section{Figure 3}

Cluster and phylogenetic analysis of gene expression patterns of Enterobacter xiangfangensis. Red indicates high gene expression, blue indicates low gene expression. Hence, colour change from red to blue indicate log10 (FPKM+1) change from large to small. The log10 (FPKM+1) values were normalized and clustered. 


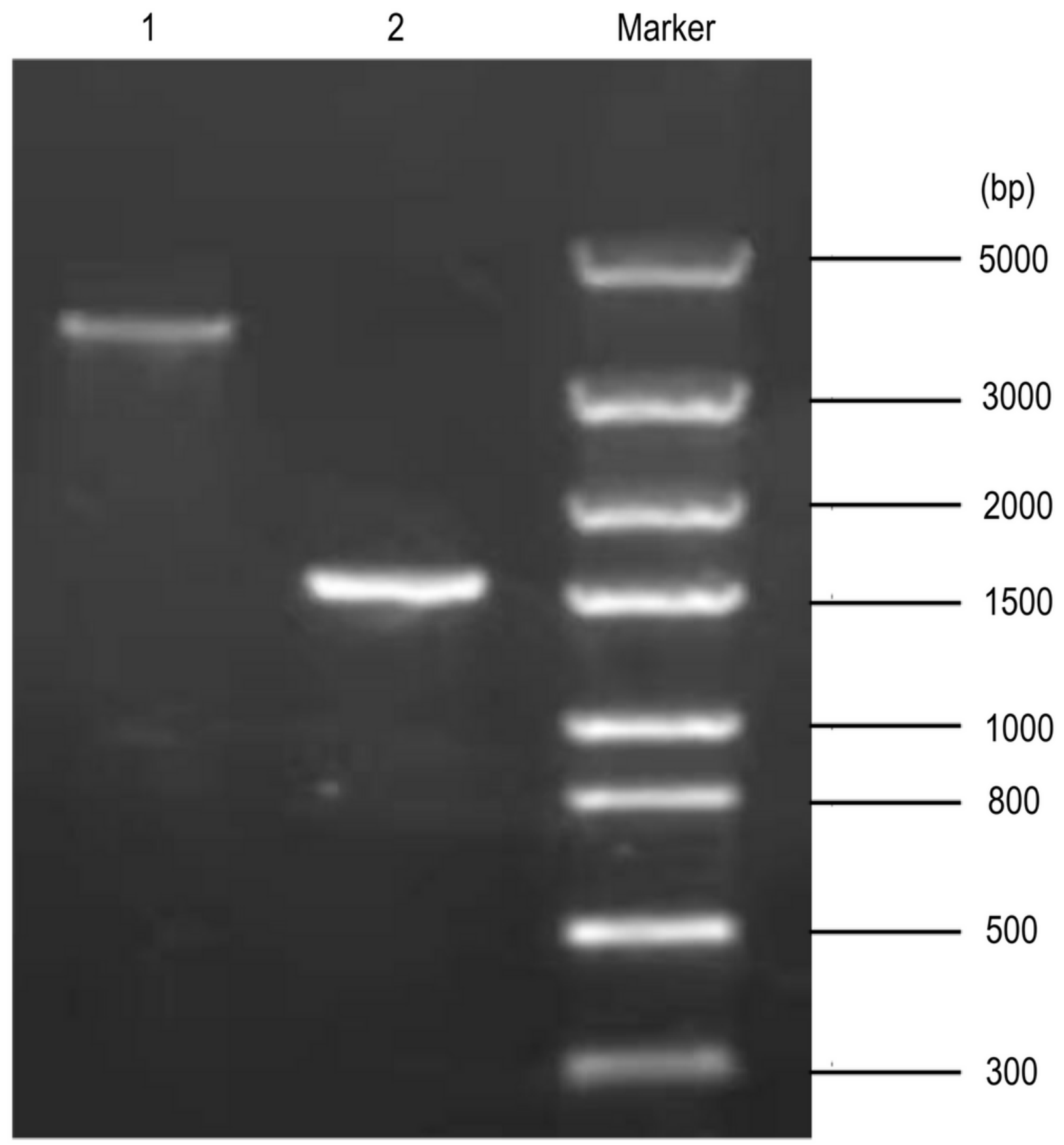

Figure 4

Construction of the ALDH gene-deficient Enterobacter xiangfangensis mutants. PCR identification of mutants with T1/T2 or T1/T3; Marker. DL5000 DNA Ladder; 1, wild-type; 2, mutant. 


\section{$\square 40 \mathrm{ng} / \mu \mathrm{l} \square 200 \mathrm{ng} / \mu \mathrm{l}$}

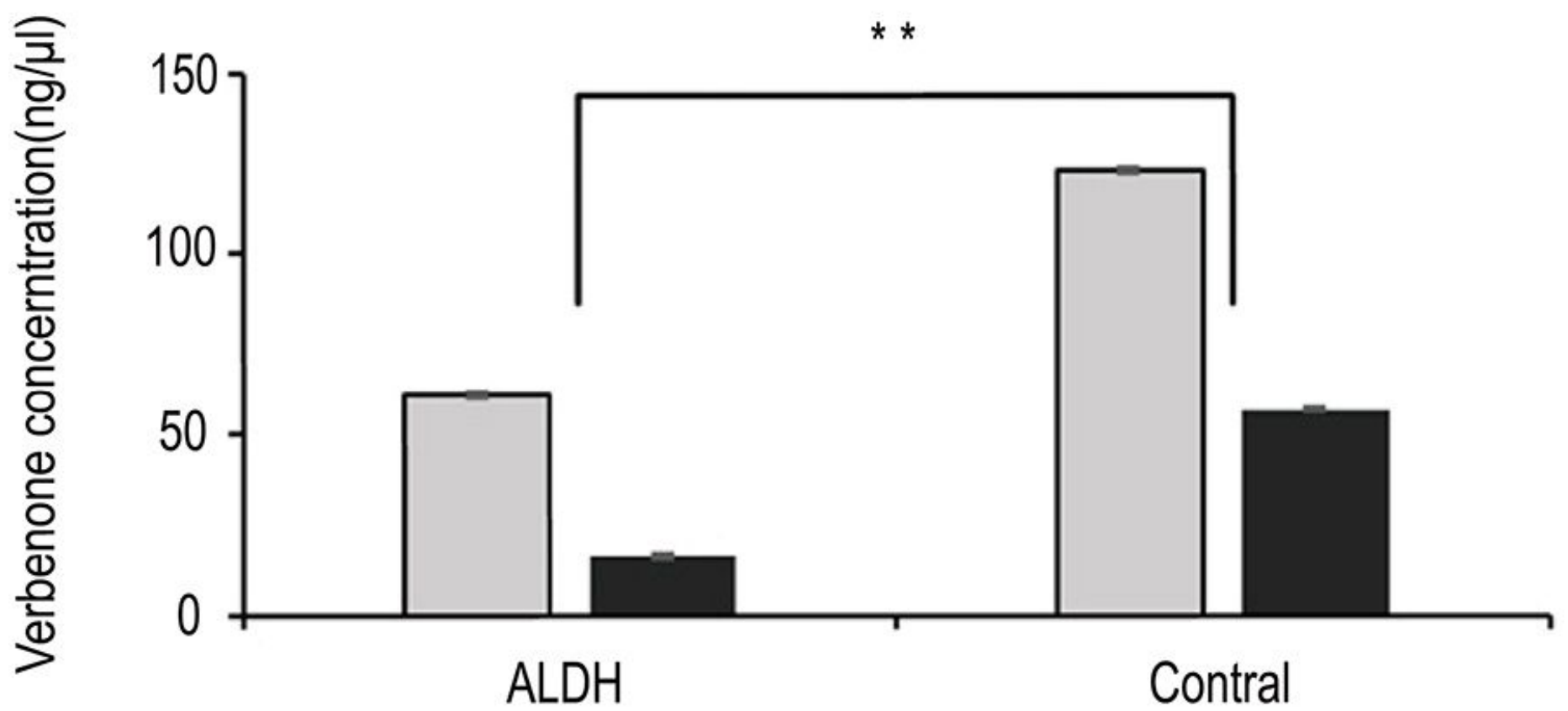

Figure 5

Verbenone production by ALDH gene mutant $E$. xiangfangensis under anaerobic environment. The amounts of verbenone produced by facultative anaerobic ALDH mutant (ALDH) and wild-type strains (control) at $40 \mathrm{ng} / \mu \mathrm{l}$ (light grey bars) and $200 \mathrm{ng} / \mu \mathrm{l}$ (black bars) cis-verbenol concentrations. Statistical analysis was performed using Dunnett's $T^{3}$ test. ** are significantly different at $P=0.05$. 